IV Congreso Internacional Estética y Política Poéticas del desacuerdo para una democracia plural 16 y 17 de octubre. Valencia

Doi: http://dx.doi.org/10.4995/CEP4.2019.10512

\title{
‘Arte agonista' como dispositivo transformador del hegemónico orden simbólico
}

\author{
Ricardo González García
}

Universidad de Cantabria, gonzalezgr@unican.es

\begin{abstract}
In the present research, we analyze how Chantal Mouffe considers the political dimension of art through its critical possibility in the face of the hegemonic symbolic order imposed by the capitalist system. To do this, we check the structure of her idea from the keys established by the revision of concepts such as "hegemony" and "antagonism" to the aim of reaching an intermediate vision that is called as agonist, which, given the impossibility of a radical antagonism but accommodating the fight against the order imposed by capitalism, it submit as a formula that, from the affections, can offer a wide range of possibilities to raise awareness of people and encourage their participation in a more plural and democratic society. From the attitude of criticism and resistance, which entails this perspective that we have been described here as "agonist art", certain activist practices work that, created different ways of subjectivation, advocate to claiming common sense in society.
\end{abstract}

Keywords: agonist art, radical democracy, white noise, organic intellectuality

\section{Resumen}

En la presente investigación se analiza cómo Chantal Mouffe plantea la dimensión política del arte a través de su posibilidad crítica ante el orden simbólico hegemónico que impone el sistema capitalista. Para ello, se comprueba que estructura su idea a partir de las claves que establece la revisión de conceptos como "hegemonía” y "antagonismo" con el objetivo de llegar a una visión intermedia que denomina como agonista, la cual, ante la imposibilidad de un antagonismo radical pero dando cabida a la lucha contra el orden que impone el capitalismo, se presente como una fórmula que, desde los afectos, pueda llegar a ofrecer una amplio abanico de posibilidades para concienciar al individuo y fomentar su participación en una sociedad más plural y democrática. Desde la actitud de crítica y resistencia, que conlleva esta perspectiva que se ha denominado aquí como "arte agonista”, trabajan ciertas prácticas activistas que, creando diferentes formas de subjetivación, abogan por reivindicar el sentido común en la sociedad.
\end{abstract}

Palabras clave: arte agonista, democracia radical, ruido blanco, intelectualidad orgánica 


\section{Introducción}

Siguiendo las premisas de Chantal Mouffe, se plantea aquí la posibilidad de un arte crítico - denominado "agonista"-, que pueda ser útil para visibilizar los problemas sociales y concienciar a la población de estar en su derecho de ejercer una razón pública o democracia radical. Dentro de las patologías hiperexpresivas que acarrea el orden simbólico hegemónico que impone el sistema capitalista, el malestar que ante ello pueda haber en la cultura y sus espacios de representación nos conduce a reflexionar sobre cómo este tipo de arte puede distinguirse de lo que Franco Berardi $(2007,222)$ denomina como "blanco rumor", para que su mensaje pueda ser recibido por el espectador.

Si se analiza cómo funciona este "esquizofrénico" sistema de excesivos flujos semióticos, para muchos de los cuales no tenemos capacidad de interpretación, podemos comprobar que guarda una contradicción intrínseca que, según Deleuze, se halla íntimamente unida al psicoanálisis, lo cual establece una conjunción entre producción de las máquinas "deseantes" y producción de enunciados como mecánica que acaba activando los flujos económicos que lo sostienen. Esta circunstancia de sobrecarga infocrática en la que el sistema basa su poder, afecta también a la producción cultural, sus códigos o los mensajes que lanza, extendiendo una red soportada en la mercantilización que también repercute en lo institucional o viceversa. El mismo Deleuze $(2005,34)$ declara que: "El último problema del esquizoanálisis no es sólo el estudio positivo de las máquinas deseantes, sino el estudio positivo de la manera en que las máquinas deseantes proceden al investimento de las máquinas sociales, sea formando investimentos de libido de tipo revolucionario, sea formando investimentos de libido de tipo reaccionario". Saber, pues, en qué medida estamos condicionados por estas "máquinas deseantes" o somos cómplices de tal situación, o de qué forma podemos reaccionar, puede representar un primer paso para poder distinguir que existe cierto tipo de arte que escapa de esa red para, a través de lo emocional ya como única fisura por la que "colarse" en el registro identitario del individuo, llegar a este con otro tipo de consignas que crítiquen el discurso hegemónico del neoliberalismo y que pueda llegar a concienciarse de situaciones de desigualdad provocadas por el propio sistema en el que se desenvuelve.

Hacer hincapié en esta posibilidad, es volver a la idea de "intelectualidad orgánica" desarrollada por Gramsci para aplicarla al territorio del arte y hacer ver, así, cómo este espacio de representación es uno de los pocos que aún posee capacidad para vincularse orgánicamente con la comunidad y transformar el hegemónico orden simbólico impuesto por el sistema neoliberal, en función de devolver al pueblo su autonomía y poder de decisión sobre las cuestiones sociales que lo conciernen. El pensamiento de Gramsci, por tanto, es el que desencadena parte de lo que desarrollan autores posteriores en defensa de la necesidad de un arte crítico, pues es mediante este por el que la conciencia de determinado momento histórico puede expresarse. De ahí que ahora más que nunca, cuando más intensamente se experimenta el desleimiento de los contornos, difuminando cualquier compartimentación disciplinar y transformando con ello la tectónica epistemológica, así como una pérdida continuada de valores que sustentaron la tradición -lo cual también repercute en cierta estabilidad ideológica-, sea necesario, desde el campo del arte, la instauración de un equilibrio pues, de lo contrario, la ausencia de un orden intelectual y moral se puede traducir en falta de evolución orgánica de la historia (Gramsci, 2007, 242).

Según esta razón, y basando la naturaleza de lo político en dos conceptos clave como son: "antagonismo" y "hegemonía" (Laclau, Moufee, 2004), que "apuntan a la importancia de aceptar la dimensión de negatividad radical que se manifiesta en la imposibilidad siempre presente del antagonismo”(Mouffe, 2014, 21), existe toda una línea artística, de Joseph Beuys a Alfredo Jaar por ejemplo, comprometida con este tipo de concienciación; practicas artísticas que, en su conjunto, se adecúan a la idea de un "arte agonista" que, más o menos cercana a la política, como "conjunto de prácticas, discursos e instituciones que busca establecer un determinado orden y organizar la coexistencia humana en condiciones que siempre son potencialmente conflictivas, ya que están afectadas por la dimensión de 'lo político"' (Ibid., 22), se muestra eminentemente cercanas al concepto de "lo político" (Mouffe, 2007), entendiendo este como la "dimensión del antagonismo que puede adoptar diversas formas y puede surgir en diversas relaciones sociales" (Mouffe, 2014, 22).

\section{Objetivos}

Desde un pensamiento que pasa por una concepción eminentemente política del mundo, Chantal Mouffe propone un "pluralismo agonístico", en su sentido más gramsciano, como modelo político que medie reconciliando posibles 
diferencias ideológicas y alternativa al pensamiento único que parece imponer el proyecto político del neoliberalismo, el cual lleva adherido un orden simbólico propio que, de algún modo, trata de hacer hegemónico. En ese sentido, Mouffe $(1999,12)$ critica dicho sistema, pues:

En esas actitudes, el pensamiento político de inspiración liberaldemocrática revela su impotencia para captar la naturaleza de lo polítíco. Pues de lo que aquí se trata es precisamente de lo político y de la posibilidad de erradicar el antagonismo. En la medida en que esté dominada por una perspectiva racionalista, individualista y universalista, la visión liberal es profundamente incapaz de aprehender el papel político y el papel constitutivo del antagonismo (es decir, la imposibilidad de constituir una forma de objetividad social que no se funde en una exclusión originaria).

Para luchar, pues, contra este poder dominante, es necesario dar cabida al conflicto, como reunión de posiciones antagónicas, para llegar a consensos que desanquilosen la hiperterritorialidad que conlleva el asentamiento del citado orden simbólico neoliberal. Por ello, es justamente en esta confrontación de contrarios donde la expresión artística puede desempeñar una función determinante, pues en la libertad de confundir lo deseable con lo posible el arte, como nivel en el que se constituye la identificación y las formas de identidad (Mouffe, 2007, 26), llega a hundir sus raíces en el imaginario social para cuestionarlo y remover conciencias.

Un tipo de arte comprometido como el que aquí se trata de destacar y podemos englobar dentro de la denominación de "agonista", ha de tener clara la confusión generalizada o "ruido blanco" a la que, interesadamente, ha tendido un sistema capitalista auspiciado por las actuales sociedades de control. Y como confusión se entiende aquí ese fenómeno que ha llevado a extrapolar conceptos propios del arte, como puede ser la estética o la creatividad, a otros sectores sociales, convirtiendo una posible función social que podía poseer el arte en mera sonoridad sinsentido, en tanto que decorativismo hedonista abierto a la especulación económica en un contexto donde también el propio conocimiento se acaba mercantilizando. La clave para conseguir el "arte agonista" que aquí se plantea y persigue, quizá pase por retomar el arte como espacio de resistencia que no siga las premisas que imponen los intereses de las empresas privadas que sustenta el sistema, sino que sea capaz de escapar del yugo alienante de homogeneidad que imponen para volverse crítico en función de los intereses que, para su propia emancipación, ha de defender la comunidad.

Dentro de este escenario, se ha de ser consciente de que la "imagen compleja", como denomina Josep María Catalá (2006), que difunde el metamedio digital trabaja a favor de hacer completamente opaca la situación, reflejando discursos interesadamente dominantes que conducen a la sociedad hacia un pensamiento único. Y aunque el arte pueda aparecer como el único espacio de representación desde el cual ofrecer resistencia a tal circunstancia, el depredador organismo en el que se ha convertido la maquinaria capitalista acaba fagocitando cualquier expresión, también las que lo cuestionan, viéndose estas neutralizadas. De ahí que realizar un arte crítico que acabe cumpliendo su función efectiva en la lucha contra el orden simbólico establecido, abriendo "vías para estrategias diferentes de oposición" (Mouffe, 2007, 59), represente una tarea ardua y complicada, pero no por ello menos necesaria sino todo lo contrario.

Por esta razón, se plantea aquí la necesidad y el alcance de un "arte agonista" que abandone la idea moderna de vanguardia, pero mantenga su espíritu crítico, pues, como ya es casi imposible establecer críticas totalmente radicales, lo que hace falta, según Mouffe $(2007,60)$, es "agrandar el ámbito de la intervención artística en una multiplicidad de espacios sociales para oponerse al programa de movilización social total del capitalismo". De ahí que se desglose, a continuación, una pequeña comparativa entre las concepciones que diferentes autores tienen ante cómo debiera ser un arte crítico para, seguidamente, profundizar en aquello que específicamente plantea Mouffe.

\section{Desarrollo}

Si bien existe concomitancias con las teorías que proponen otros autores en cuanto al potencial político que posee el arte, como la representatividad del "régimen estético" que propone Jacques Rancière (2005), quien conceptualiza lo político en el arte a partir de convergencias heterogéneas; una política estética en la que aquello que visibilizan las prácticas artísticas reconfigura lo sensible, o la militancia y compromiso del "arte crítico" que desarrolla Nelly Richard (2007), más próxima a Mouffe pero poniendo el acento en la conceptualización de lo político a partir de la modulación de la 
tectónica interna de la obra de arte, el concepto agonista aplicado al arte posee, como característica fundamental, estar basado, como se ha mencionado, en el hecho de ubicar el "antagonismo" en el centro del contexto del orden simbólico hegemónico para hacerlo implosionar. Curiosamente para ello, Mouffe directamente pone el énfasis en la producción de las subjetividades que se necesita para tal fin, mientras que Rancière habla de modos de subjetivación. Mientras que el segundo trata de objetivar desde un terreno metodológico, la primera convoca la parcela de las pasiones y los afectos del individuo como último reducto que, puede, aún no se halle "zombificado" por el sistema capitalista, terreno por el cual poder hacer "despertar" a los sujetos y que comiencen a adquirir conciencia.

Según expresa Mouffe (2014, 97): “el capitalismo actual depende cada vez más de las técnicas semióticas para crear los mundos de subjetivación. En la producción moderna, el control de las almas -tal como lo formula Foucault- juega un papel estratégico en el dominio de los afectos y las pasiones". Incidiendo en esa dimensión emocional, por tanto, el arte, siempre político para Mouffe, es capaz de acelerar la visualización de diferentes problemáticas que critican al sistema, presentando una baraja de posibilidades y alternativas. Según este modelo que propone la autora, se puede decir que solo a través de tocar esta dimensión aludida el individuo es capaz de identificarse para, consecuentemente, generar un cambio que lo conduzca hacia la crítica del orden simbólico dominante, lo cual correspondería a algo así como quitarse una venda de los ojos para cerciorarse de la manipulación a la que le expone un sistema que tantos sueños emancipatorios le prometía. De este modo, la experiencia estética acaba actuando como catalizador que dispara una acción interna en la reflexión del espectador.

Dada la reacción que el arte -tomado en su sentido crítico y, por tanto, como arma política- puede desencadenar, ella concibe a sus artífices, los artistas, como autenticos “intelectuales orgánicos”, retomando un concepto desarrollado por el mismo Gramsci. Es decir, como importantes piezas claves del sistema que, aunque no puedan ocasionar un quiebro radical a la situación presente que critican, son capaces, en cambio, de presentarse lo suficientemente subversivas/os como para modelar y transformar ese orden simbólico hegemónico que sibilinamente impone el sistema capitalista. Subversión para la disrupción que Rancière, por ejemplo, concibe como disensos y desacuerdos, los cuales, en definitiva, introducen una perspectiva subjetivista en el horizonte político al cual el individuo tiende en función de su propia identificación, lo cual es sinónimo de un posible porvenir político que está por enunciar y definir, siendo, para ello, el indiduo convocado en todo momento. Por esta razón, es en la "línea de fuego" del disenso disrruptivo desde la cual el sujeto se manifiesta en su máxima potencialidad política.

En definitiva, estos tres enfoques plantean la posibilidad de una obra de arte como dispositivo crítico de situaciones sociales. En función de la "impugnación de la hegemonía dominante", la cuestión que se plantea, como señala Mouffe (2007, 67), “es el tipo de identidad que las prácticas artísticas críticas deben ir encaminadas a fomentar”. Por ello, según el filtro agonista desde el cual se puede concebir la práctica artística, el fomento del disenso es capaz de vover visible lo que el consenso dominante suele oscurecer y borrar. Disenso constituido, en definitiva, "por una diversidad de prácticas artísticas encaminadas a dar voz a todos los silenciados en el marco de la hegemonía existente" (Ibid.). Así, se puede encontrar,en esa línea crítica diversidad de prácticas artístico-activistas: nuevas luchas urbanas como «Reclaim the streets» en Gran Bretaña o «Tute Bianche» en Italia, pasando por las campañas «Alto a la publicidad» en Francia y «Nike Ground-Rethinking Space» en Austria, o las eficaces sátiras de la ideología neoliberal que proponen The Yes Men, según Mouffe (Ibid. p. 68). Manifestaciones, en suma, totalmente necesarias para "desbaratar la imagen agradable que el capitalismo de las grandes empresas está intentando difundir, al situar en primer plano su carácter represivo", y contribuir a la construcción de nuevas subjetividades como dimensión decisiva del proyecto democrático radical (Ibid., 70).

En un contexto contemporáneo donde las industrias culturales no siguen los designios que esperaba la escuela de Frankfurt, para la cual estas debían cumplir un papel activo manteniendo un espíritu crítico que fomentara la resistencia ante el poder hegemónico, se ven estas ahora sometidas a una disolución e hibridación con otras "esferas del trabajo, la acción política y la reflexión intelectual” (Mouffe, 2014, 94), debido a la homogeneización característica del sistema capitalista. Ocasionando esta situación nuevas correspondencias entre individuos, con nuevas configuraciones provocadas por la distinta relación entre el arte y el trabajo, el objetivo de las prácticas artísticas debería ser:

Alentar el desarrollo de esas nuevas relaciones sociales que son posibles por la transformación del proceso de trabajo. Su tarea principal es la producción de nuevas subjetividades y la elaboración de nuevos mundos. En la 
actual situación, lo que se necesita es una ampliación del campo de intervención artística, con artistas operando en una multiplicidad de espacios sociales fuera de las instituciones tradicionales, a fin de oponerse al programa de movilización social del capitalismo (Ibid., 95).

Dentro de esa interactuación crítica con la esfera social, el potencial político, desde la resistencia crítica, que pueden desarrollar las prácticas artísticas, debiera de concebirse desde intervenciones agonistas, según Mouffe. Porque, en definitiva, "el enfoque agonista percibe al arte crítico como constituido por una diversidad de prácticas artísticas que ponen de relieve la existencia de alternativas al actual orden pospolítico" (Mouffe, 2014, 99). Por tanto, al crear nuevas formas de subjetividad y tocar la dimensión emocional del individuo, llevan a este a respuestas de carácter afectivo que le hacen concienciarse de la situación al imaginar posibles opciones que van más alla de las que ofrece el orden hegemónico imperante.

\section{Conclusiones}

Asumiendo que toda práctica artística contribuye a reproducir un sentido común remarcando, por ello, su inherente sentido político, existen algunas que, por su intención antagonista, inciden con más insistencia en la crítica al orden hegemónico establecido por las instituciones de poder que defienden un pensamiento de corte neoliberal. Este activismo artístico cumple su misión al ser percibido como acciones contrahegemónicas que reaccionan a la constante apropiación que, de la estética y otras cuestiones propias del arte, ejerce el sistema capitalista para perpetuarse difundiendo su orden simbólico. Aún así, este activismo sería incapaz de luchar por una democracia radical si no interacciona a diferentes niveles de la esfera social. El pluralismo agonístico que, por tanto, pueden conllevar las prácticas artísticas en persecución de una democracia radical, se orientan a crear condiciones de posibilidad que expresen la realidad de una confrontación, de un antagonismo entre el orden simbólico que difunde el sistema capitalista y una crítica al mismo, a través de acciones activistas que se desarrollan desde la resistencia. A fin de cuentas, estas formas de subjetivación defiende un sentido común, o razón pública, teniendo en consideración la dimensión emocional del individuo, pues posiblemente resida ahí la mejor vía de hacerle ver y tomar conciencia de las condiciones de desigualdad que provoca dicho sistema y su orden simbólico. No se trata de relegar, según estas premisas, las pasiones al ámbito privado sino llevarlas, en tanto que dispositivos en los que el individuo puede verse identificado dentro de la pluralidad de expresiones, a la esfera pública para conseguir objetivos de carácter democrático.

Siguiendo las argumentaciones aquí expuestas, se comprueba que las prásticas artísticas concebidas desde la vertiente no antagonista sino agonística que defiende Mouffe, pueden luchar contra el orden simbólico hegemónico establecido por la ideología noeliberal, pues tomando la imposibilidad de destrucción de este, desde lo que supondría una postura antagónica radical, se puede llegar a una especie de "consenso conflictual" que legitime sus demandas. En este campo de "batalla" ya no hay enemigos sino adversarios, pues hay que tener en cuenta que mientras en la lucha antagonista no se comparte ninguna base común, en la lucha agonista se comparte un mismo espacio simbólico cuyo orden se ha de variar: se lucha con las mismas "armas" que el adversario en función de revitalizar la democracia.

\section{Referencias}

BERARDI, F. (2007). Generación post-alfa. Patologías e imaginarios en el semiocapitalismo. Buenos Aires: Tinta Limón.

CATALÁ, J. M. (2006). La imagen compleja: la fenomenología de las imágenes en la era de la cultura visual. Barcelona: Universitat Autónoma de Barcelona.

Deleuze, G. (2005). Derrames entre el capitalismo y la esquizofrenia. Buenos Aires: Cactus.

Gramsci, A. (2007). Prison Notebooks 3. Nueva York: Columbia University Press.

LaClau, E., Mouffe, C. (2004). Hegemonía y estrategia socialista. Hacia una radicalización de la democracia. Buenos Aires: FCE.

MoufFe, C. (2014). Agonística. Pensar el mundo políticamente. Buenos Aires: Fondo de Cultura Económica.

MoufFe, C. (2007). Prácticas artísticas y democracia agonística. Barcelona: Universitat Autónoma de Barcelona.

Mouffe, C. (2007). En torno a lo político. Buenos Aires: Fondo de Cultura Económica. 
Mouffe, C. (1999). El retorno de lo político. Comunidad, ciudadanía, pluralismo, democracia radical. Barcelona: Paidós.

RANCIÈRE, J. (2005). Sobre políticas estéticas. Barcelona: Universitat Autónoma de Barcelona.

RichARD, N. (2007). Fracturas de la memoria. Arte y pensamiento crítico. Buenos Aires: Siglo XXI. 